\title{
INFORME COMITÉ DE ÉTICA DE LA ASOCIACIÓN COLOMBIANA DE TERAPIA OCUPACIONAL
}

La Junta Directiva de la Asociación Colombiana de Terapia Ocupacional durante el período 1997-1998 tuvo entre sus tareas motivar a sus asociados a participar en la creación del Comité de Ética. Se invitó a las ex presidentes para conformarlo, obteniendo respuesta de algunas de ellas.

El día 7 de septiembre de 1998 en la sede de Sociedades Científicas la Junta Directiva en reunión con las representantes: María José Serpa de la Universidad del Rosario, Aleyda Fernandez de la Universidad Nacional, Patricia Gómez de la Escuela Colombiana de Rehabilitación y Cassandra Ramírez de la Fundación Manuela Beltrán, se determinó que el Comité de Etica quede conformado por las Terapeutas Alicia Trujillo R., María Eugenia Caicedo, Margarita González, Aida Navas, Adriana Ordúz de Cáceres, expresidentas con reconocido prestigio dentro de la comunidad de terapeutas. Completan este Comité las terapeutas Aleyda Fernandez como representante de las Universidades y Ana María Gómez, representante de la Asociación.

El Comité a la fecha ha venido realizando acciones de organización y actualización referente al anterior Código de Ética teniendo en cuenta el desarrollo y compromiso profesional. A continuación se presenta un avance en cuanto al reglamento interno del Comité de Ética.

\section{COMITÉ DE ÉTICA DE LA ASOCIACIÓN COLOMBIANA DE TERAPIA OCUPACIONAL}

\author{
REGLAMENTO INTERNO
}

\section{DEFINICIÓN:}

La Asociación Colombiana de Terapia Ocupacional, sus miembros y los terapeutas ocupacionales que ejercen en el país, están comprometidos con el estudio, la 
gestión, ejecución en programas de promoción, desarrollo y recuperación ocupacional de personas y grupos.

El Comité de Ética es una instancia de la Asociación Colombiana de Terapia Ocupacional que se encarga de estudiar, divulgar y sancionar asuntos relacionados con los valores y normas que deben regir el comportamiento profesional de los terapeutas ocupacionales, de conformidad con los principios y estándares de la profesión y con el marco político-legal vigente.

\section{PROPÓSITO:}

Fomentar el comportamiento de los Terapeutas Ocupacionales, caracterizado por principios éticos que enaltezcan la profesión y contribuyan a su posicionamiento social.

\section{OBJETIVOS:}

1. Estudiar los principios y valores éticos de la Terapia Ocupacional en el contexto de la sociedad contemporánea.

2. Proponer investigaciones sobre temas y procedimientos relacionados con el comportamiento ético.

3. Estudiar las condiciones personales que deben caracterizar el comportamiento ético de los terapeutas ocupacionales en beneficio propio, de la profesión y de la sociedad colombiana.

4. Educar y mantener actualizada e informada a la comunidad profesional en temas de ética.

5. Resolver los dilemas éticos del ejercicio que se reportan a la Asociación Colombiana de Terapia Ocupacional para tomar decisiones sobre las acciones a seguir.

6. Servir como órgano consultor para otras entidades en relación con debates éticos. 
7. Establecer su reglamento interno.

8. Otras que le asigne la Junta Directiva.

9. Responder ante la Junta Directiva por las responsabilidades que le ha encomendado.

10. LOS MIEMBROS DEL COMITÉ:

Para ser miembro del Comité de Etica se requiere gozar de reconocida solvencia moral, e idoneidad profesional.

Haber ejercido la Terapia. Ocupacional por espacio no inferior a 8 años o haber desempeñado la cátedra universitaria por lo menos durante 4 años.

Los Miembros del Comité serán nombrados por la Junta Directiva por un período de 2 años. El nombramiento de los Miembros del Comité será ratificado por Asamblea General.

ANA MARÍA GÓMEZ G.

Vicepresidente 